\title{
Socio-economic dependence on the incidence of tuberculosis in Jos, North central Nigeria
}

\author{
Bigwan E. I. ${ }^{1}$, Ohaeri M. C. ${ }^{2}$, Vem T. S. ${ }^{1}$, Sheyin Z. ${ }^{1}$, Umar A. ${ }^{3}$, Olukose O. J. ${ }^{4}$, Wuyep P. ${ }^{5}$, \\ Gyang B. ${ }^{5}$, Chollom S. C. ${ }^{6}$ \\ ${ }^{1}$ Department of Medical Laboratory Science, University of Jos, P.M.B.2084, Jos, Nigeria \\ ${ }^{2}$ FCVMLT, National Veterinary Research Institute, Vom, Plateau State, Nigeria \\ ${ }^{3}$ Department of Biological Sciences, Federal University, Dutsin Ma, Katsina State \\ ${ }^{4}$ Laboratory Department, Faith Alive Foundation, Jos \\ ${ }^{5}$ Plateau State Specialist Hospital, Jos, Nigeria \\ ${ }^{6}$ National Veterinary Research Institute, Vom, Plateau State, Nigeria
}

\section{Email address:}

emabigwan@yahoo.com (Bigwan E. I.)

\section{To cite this article:}

Bigwan E. I., Ohaeri M. C., Vem T. S., Sheyin Z., Umar A., Olukose O. J., Wuyep P., Gyang B., Chollom S. C.. Socio-Economic Dependence on the Incidence of Tuberculosis in Jos, North Central Nigeria. Science Journal of Public Health.

Vol. 1, No. 5, 2013, pp. 235-238. doi: 10.11648/j.sjph.20130105.19

\begin{abstract}
Background: Mycobacterium tuberculosis remains a disease of serious public health concern due to its high tendency of person-person transmission, morbidity, and mortality. Objective: This study aimed at determining the prevalence of AFB in relation to some socioeconomic variables within the study area. Methods: Sputum samples were collected from three hundred and three (303) patients with suspected cases of pulmonary tuberculosis in Jos, Nigeria. The samples were examined using Ziehl Neelsen method. Structured questionnaires were administered to obtain some demographic data from patients that consented. Results were tested statistically for significance at $p<0.05$ using Chisquare test. Results: Of the samples examined, 29(9.60\%) were positive for AFB .Statistically the study reveals that occupational status and educational status does not have any effects on the prevalence $(\mathrm{p}>0.05)$. Income status of individuals showed a significant effect on the prevalence $(\mathrm{p}<0.05)$.Conclusion: Pulmonary tuberculosis was recorded more among patients with low socio-economic status. There is need for a more collaborative efforts and political will by the government and non-governmental agencies in order to eliminate the infection in the nearest future.
\end{abstract}

Keywords: Socioeconomic Status, Tuberculosis, Nigeria

\section{Introduction}

Tuberculosis (TB) continues to be one of the leading causes of disease, disability, and death. Seventy-five percent of people with TB belong to the economically active age group (15-54 years) and $95 \%$ of the cases and $99 \%$ of deaths occur in developing countries [1].It is a disease beyond the borders able to pass through many international borders unnoticed or unchecked as a result of migrations, epidemics, wars and uncontrolled increase in world population. It remains a serious public health problem in developing countries where its incidence is increasing as a result of poverty, malnutrition, overcrowding and deficient health care [2].

Although TB is a worldwide problem, Nigeria is one of the five countries in the world with the highest prevalence rate. The best way to prevent the spread of the disease in any community is to treat the cases immediately to prevent it from infecting other members of the community. If most of those infected are detected early and provided effective treatment, they will go back to the community and society, and be economically productive. With the implementation of DOTS programme in Nigeria, there has been an improvement in treatment success recorded in the last couple of years. Nevertheless, the treatment success so far recorded fall short of the WHO set target in terms of case detection and treatment cure rate [3].

Tuberculosis persists as a major cause of human mortality and morbidity, affecting almost a third of the world's population [4]. Sputum microscopy and sputum culture have been advocated as two useful tools for diagnosis of pulmonary tuberculosis. However, few 
tuberculosis-control programmes in low-income countries have access to culture facilities in their primary-care diagnostic centers. Moreover, culture for acid-fast bacilli (AFB) takes 6-8 weeks to be interpretable, which limits the usefulness of culture as a first-line diagnostic test. Under these circumstances, sputum smear examination for AFB is the most useful test for diagnosis of pulmonary tuberculosis In the absence of readily available sputum culture in lowincome countries, most cases of smear-negative tuberculosis are diagnosed on the basis of clinical presentation, radiological findings, and other laboratorybased indicators [5].

Tuberculosis is a social disease with medical aspects. The social factors include many non-medical factors such as poor quality of life, poor housing, overcrowding, under nutrition, lack of education, large families and lack of awareness of cause of illness [6].

TB occurs in every part of the world. In 2010, the largest number of new TB cases occurred in Asia, accounting for $60 \%$ of new cases globally. However, Sub-Saharan Africa carried the greatest proportion of new cases per population with over 270 cases per 100000 population in 2010. People infected with TB bacteria have a lifetime risk of falling ill with TB of $10 \%$. However persons with compromised immune systems, such as people living with HIV, malnutrition or diabetes, or people who use tobacco, have a much higher risk of falling ill [7].

This study aimed at determining the sociodemographic characteristics of patients presenting with pulmonary $\mathrm{TB}$ (PTB) in Jos, North Central Nigeria.

\section{Materials and Methods}

\subsection{Study Area}

Plateau State of Nigeria covers an area of 26,899 square kilometers is located in the Middle Belt zone. It is located between latitude $80^{\circ} 24^{\prime} \mathrm{N}$ and longitude $80^{\circ} 32^{\prime}$ and $100^{\circ} 38^{\prime}$ east. Plateau gets its name from the Jos Plateau. The State is also known as the Home of Peace and Tourism. It enjoys a relatively temperate climate, with average temperatures between $18^{\circ} \mathrm{C}$ and $22^{\circ} \mathrm{C}$. Based on the 2006 population census figures, Plateau state had an estimated population of $3,178,712$ people [8]. The main occupation in the rural areas is farming, while those in urban areas are civil servants, traders and students. The two major hospitals Jos University Teaching Hospital (JUTH) and Plateau Specialist Hospital (PSSH) serve as referral centers for the primary and secondary health care facilities in the area. Plateau State Specialist Hospital and Faith Alive Foundation are situated within Jos city and they serve patients mostly within the state.

\subsection{Ethical Consideration}

Ethical clearances were obtained from Jos University Teaching Hospital, Plateau Specialist Hospital, and Faith Alive Foundation before the commencement of the work.

\subsection{Study Population}

The study population focused on all Patients within the age range 15 years and above with suspected cases of pulmonary tuberculosis attending Plateau Specialist Hospital and Faith Alive Foundation.

\subsection{Sampling Methodology}

A structured questionnaire was administered randomly to patients who gave their consent in other to obtain some useful bio-data.

\subsection{Sample Collection}

The sample collection were done with the assistance of Medical personels. The patients were given sterile universal bottles in which they produced three samples (one spot, one early morning and one spot).

\subsection{Sample Analysis}

Three consecutive sputum samples were collected in leak proof universal plastic containers and stained using ZiehlNeelsen's method and examine in accordance with standard methods.

Three smears were prepared from each patient, heat fixed and stained using Ziehl-Neelsen technique as follows: Strong carbol fuchsin was flooded on the slides and steamed, it was then allowed to stain for 5 minutes followed by decolourization with $3 \%$ acid-alcohol and washed with water and then counterstained with $0.3 \%$ methylene blue for 1 minute, washed with water and allowed to air-dry before examination for AFB [9].

\subsection{Microscopic Examination of Slides/Grading of Microscopy Results}

The stained smears were examined with the Olympus light, binocular microscope under the oil immersion objective, scanning all fields at high power field for the presence of bright red slender rods, the presence of which signified positive AFB and the absence, negative. The microscopy revealed the tubercle bacilli being bright red on a blue background; straight or slightly curved, quite short $(1-4 \mu \mathrm{m})$ often granular, arranged in groups of 3-10 bacilli close together like bits of string. The grading of the microscopy was done in accordance to standard method as follows:

$1-9 / 100$ fields $-1+; 1-9 / 10$ fields $-2+; 1-9 / 1$ field $3+; 9 / 1$ field $-4+$ and Negative -0 [9].

\section{Results}

Three hundred and three (303) sputum samples were examined for AFB from the study area. Out of the 303 sputa, $29(9.60 \%)$ were positive for AFB. Table 1 shows the prevalence in relation to occupational status. The result revealed that farmers had the highest prevalence with $4(14.28 \%)$,followed by other groups which include drivers, 
full house wife, apprentice had $7(11.48 \%$ ), business people had 10(10.42\%), Students/applicants had 5(7.35\%), while civil servants had the least with $3(6.0 \%)$. Statistically, 0ccupational status does not have any effect in this relationship $(\mathrm{p}>0.05)$.

Table 2 shows the prevalence of AFB in relation to educational status. Out of all the sputa examined, secondary level had the highest with $11(11.70 \%)$, primary had $9(10.71 \%)$, while tertiary and non formal had the lowest with $7(8.86 \%)$ and $2(4.35 \%)$ respectively. Statistically, educational status does not have any effect in this relationship $(\mathrm{p}>0.05)$.

Table 3 shows the prevalence based on the monthly income of the subjects. The result indicates that people within income group of $>5000$ had the highest with $13(6.31 \%)$, followed by income group 5000-20,000 with $11(16.42 \%)$, income group $21,000-50,000$ had 5(19.23\%) while the few individuals within the higher income groups recorded none. This result showed a significant association $(\mathrm{p}<0.05)$

Table 1. Distribution of Acid-Fast Bacilli in relation to Occupation

\begin{tabular}{lll}
\hline Occupation & No. Screened & No. positive (\%) \\
\hline Civil servants & 50 & $3(6.00)$ \\
Business & 96 & $10(10.42)$ \\
Students/Applicants & 68 & $5(7.35)$ \\
Farmers & 28 & $4(14.28)$ \\
Others & 61 & $7(11.48)$ \\
Total & 303 & $29(9.60)$ \\
\hline X2=5.31 DF=4 & $\mathrm{P}>0.05$ &
\end{tabular}

Table 2. Distribution of Acid-Fast Bacilli in relation to Educational status

\begin{tabular}{lll}
\hline Education & No. Screened & No. positive (\%) \\
\hline Non-formal & 46 & $2(4.35)$ \\
Primary & 84 & $9(10.71)$ \\
Secondary & 94 & $11(11.70)$ \\
Tertiary & 79 & $7(8.86)$ \\
Total & 303 & $29(9.60)$ \\
\hline
\end{tabular}

$\mathrm{X} 2=6.17 \quad \mathrm{DF}=3 \quad \mathrm{P}>0.05$

Table 3. Distribution of Acid-Fast Bacilli in relation to Income

\begin{tabular}{lll}
\hline Monthly Income (\#) * & No. Screened & No. positive (\%) \\
\hline$<5000$ & 206 & $13(6.31)$ \\
$5000-20000$ & 67 & $11(16.42)$ \\
$21000-50000$ & 26 & $5(19.23)$ \\
$51000-100000$ & 1 & $0(0.00)$ \\
$101000-200000$ & 1 & $0(0.00)$ \\
$\geq 200000$ & 2 & $0(0.00)$ \\
Total & 303 & $29(9.60)$ \\
\hline
\end{tabular}

$\mathrm{X} 2=36.20 \quad \mathrm{DF}=5 \quad \mathrm{P}<0.05 * \# 160$ 0fficial exchange rate to 1USD at the time of the study

\section{Discussion}

The result obtained in this study reveals that of the three hundred and three (303) sputum samples examined for AFB using Ziehl Neelsen staining technique, 29(9.60\%) were positive for AFB. Considering the fact that sputum smear microscopy is less sensitive to sputum culture in tuberculosis diagnosis, and with the number of positivity obtained, it is obvious that the study area is endemic to tuberculosis. The result of this study agreed with the findings of Olowe and Famojuro [10] who reported a prevalence of $10.5 \%$ in Osogbo, Southwestern Nigeria while Nwachukwu et al. [11] reported a slightly higher prevalence of $16.83 \%$ in some parts of Abia, Southeastern Nigeria. Aderemi et al. [12] reported a prevalence of $7.1 \%$ among suspected new tuberculosis patients attending University College Hospital Ibadan while Itahl and Udofia [13] reported a prevalence of $31.7 \%$ Southeastern Nigeria which is far higher than what was obtained in this study.

The prevalence of AFB in relation to educational status showed that of all the sputa examined, secondary school holders had the highest with 11(11.70\%), while those with non formal level of academic attainments had the least with $2(4.35 \%)$. This implies that educational attainment does not influence the spread of the infection. Statistically, educational status does not have any effect in this relationship $(p>0.05)$ this was in consonance with an earlier finding [14].

The findings in this study reveals that farmers had the highest prevalence with $4(14.28 \%)$ while civil servants had the least with $3(6.00 \%)$. Based on the occupational status considered in this study, the prevalence of the infection had no influence on the basis of occupational differences $(p>$ 0.05 ) this was in agreement with a study carried out in Addis Ababa, Ethiopia [14].

The income status of individuals is also a factor in influencing the spread of the disease as seen in this study. The spread is more associated with low income earners than the rich. The findings revealed that all the smear positive individuals were within the monthly income below $5000-50,000$ while income earners above 50,000 recorded no cases of pulmonary tuberculosis. This study agreed with a report from The National Bureau of Statistics in 2005 that $54.4 \%$ of Nigerians live below the poverty line (US\$1.0). Poor nutritional status and overcrowding increase the risk of transmitting and developing TB amongst family members. In addition to women, other vulnerable population groups that live in congregate settings including prison inmates, armed forces personnel, and socially marginalized and displaced persons pose special challenges for Tuberculosis control [15].

\section{Conclusion}

The study reveals that low socio-economic status plays significant role in the transmission of tuberculosis. This study suggest that with government's political will in eradicating poverty and provision of a good health care delivery system ,the control and prevention of tuberculosis will be more effective in the country. The need for serious enlightenment campaigns on the prevention and control strategies in the study area can be very useful in reducing the transmission of the infection. This can be effectively 
done through collaboration between the government, nongovernmental, and religious organizations.

\section{Acknowledgements}

We thank the authorities of Plateau State Specialist Hospital and Faith Alive Foundation, for granting the permission to carryout the study among the study population in their facilities and also we appreciate the assistance rendered to us by the staffs of the facilities.

\section{References}

[1] World Health Organization. An Expanded DOTS Framework for Effective Tuberculosis Control, WHO/CDS/TB/2002.297, Geneva, Switzerland, 2002.

[2] Ankrah TC. The history of tuberculosis and its resurgence in the community. West Afr J Med. 1997; 16: 1-5

[3] Erah PO, Ojieabu WA. Success of the Control of Tuberculosis in Nigeria: A Review. Intern J of Health Res. 2009; 2(1):3-14 (e214p21- 32).Available at http://www.ijhr.org

[4] Lauzardo M, Ashkin D. Phthisiology at the dawn of the new century. Chest. 2000; 117: 1455-73.

[5] Siddiqi K, Lambert M, Walley J. Clinical diagnosis of smear-negative pulmonary tuberculosis in low-income countries: the current evidence. Lancet Infect Dis. 2003; 3:288-96. http://infection.thelancet.com

[6] Nirupa CG, Sudha GT, Santha TC, Ponnuraja CR, Fathima RV, Chandrasekharan VK, Jaggarajamma K, Park K. Textbook of Preventive and Social Medicine. 2005.18 $8^{\text {th }}$ ed. $\mathrm{M} / \mathrm{s}$ Banarsides Bhanat.
[7] WHO. Tuberculosis FACT SHEET 2011 PDF http://www.who.int/tb/publications /2011/factsheet_tb_2011.pdf.Accessed on $1^{\text {st }}$ June, 2012

[8] http://en.wikipedia.org/wiki/Plateau_State. Accessed on $15^{\text {th }}$ January, 2013

[9] World Health organization: TB monitoring, No. 30 strategy and Operation monitoring and evaluation 2004. http://www.who.int/gtb/en.Accessed on $24^{\text {th }}$ June, 2009

[10] Olowe OA, Famojuro HB. Laboratory Identification of Pulmonary TB using simple rapid techniques in Osogbo South Western Nigeria. Res J of Med Scie. 2010; 4(3):227230

[11] Nwachukwu NC, Orji A, Kanu IO. Epidemiology of Pulmonary Tuberculosis in some parts of Abia State, Federal Republic of Nigeria. Asian J of Epidemiol. 2009; 2(1): 1319

[12] Aderemi OK, Obaseki FA, Ishola OC, Ibrahim KK. Multi drug Resistance to Mycobacterium tuberculosis in a tertiary Hospital. J of the Med Assoc. 2007; 99(10): 1185-1189

[13] Itahl AY, Udofia SM. Epidemiology and Endemicity of Pulmonary Tuberculosis in Southeastern Nigeria. Asian $J$ Trop Med Public Health. 2005; 36(2):317-23

[14] [14] Deribew A, Negussu N, Melaku Z, Deribe K. Investigation Outcomes of Tuberculosis Suspects in the Health Centers of Addis Ababa, Ethiopia. PLoS One. 2011; 6(4):e18614.

doi: 10.1371/journal.pone.0018614.PMCID:PMC3079716.h ttp://dx.doi.org/10.1371/journal. Pone0018614.Accessed on 15th January, 2013

[15] http://www.ccmnigeria.org/index.php?Itemid=0\&option=co $\mathrm{m}$ _content\&view $=$ article\&id $=88$ last updated on 31 December, 2009. Accessed on $22^{\text {nd }}$ August, 2010. 